\title{
Analisis Parameter Anomali SP Menggunakan Metode Inversi Non linier Pendekatan Linier
}

\author{
Fajriani*1 $^{1}$, Hardi Hamzah ${ }^{2}$, Wahyu Srigutomo ${ }^{3}$, Prihandhanu Mukti Pratomo ${ }^{4}$ \\ ${ }^{1}$ Universitas Samudra \\ ${ }^{2}$ Univeritas Sulawesi Barat \\ ${ }^{3,4}$ Institut Teknologi Bandung \\ e-mail: *11 fajriani@unsam.ac.id, ${ }^{2}$ hardi@unsulbar.ac.id, ${ }^{3}$ wahyu@ fi.itb.ac.id, \\ ppmukti.pratomo@gmail.com
}

\begin{abstract}
Abstrak
Interpretasi anomali self-potential (SP) model geometri sederhana (fixed geometry) sederhana, dilakukan untuk menghitung kedalaman, sudut polarisasi benda, moment dipole listrik, dan bentuk struktur benda dibawah permukaan yang mempengaruhi data SP yang diamati diatas permukaan. Dalam mengidentifikasi parameter anomali SP akibat dari model fixed geometry dibawah permukaan bumi dapat dilakukan dengan cara pemodelan inversi. Dalam tulisan ini pemodelan inversi diselesaikan menggunakan pendekatan linier dengan metode least-square terbobot dan metode Levenberg-Marquardt. Kedua metode ini diaplikasikan untuk menentukan nilai parameter dari anomali self-potential akibat struktur sesar, dengan menganggap struktur sesar menyerupai bentuk lempeng. Metode least-square terbobot dan Levenberg-Marquardt mampu mengikuti pola hasil data pengukuran di lapangan. Kedua metode inversi tersebut efisien karena proses perhitungannya yang relatif singkat serta nilai parameter model struktur lempeng hasil perhitungan kedua metode tersebut menunjukkan hasil yang sama hanya terdapat sedikit selisih perhitungan pada nilai kemiringan sudut lempeng.
\end{abstract}

Kata kunci: anomali self-potential, fixed geometry, pendekatan linier

\section{PENDAHULUAN}

Metode Self-Potential (SP) merupakan salah satu metode geofisika pasif yang prinsip kerjanya adalah mengukur tegangan statis alam pada titik - titik di permukaan tanah. Metode SP bertujuan untuk mendapatkan anomali beda potensial yang berasosiasi dengan struktur bawah permukaan. Anomali self-potential dapat dihasilkan oleh mekanisme difusi membran, potensial bioelektrik, streaming potensial, dan potensial mineral Telford (1990). Metode SP biasanya digunakan untuk eksplorasi sulfida, hidrologi, aktivitas gunungapi dan sistem geothermal, eksplorasi hidrokarbon, arkeologi dan geofisika lingkungan.

Interpretasi anomali self-potential dapat dilakukan secara kualitatif dan kuantitatif, bergantung dari tujuan investigasi, jumlah data, kualitas data, ketersediaan informasi geologi, struktur hidrologi, dan komputasi. Analisis kualitatif diperoleh dengan mengamati bentuk kontur, amplitude, polarisasi positif dan negatif dari anomali SP yang diamati untuk memberikan informasi lokasi sumber yang prospektif. Sedangkan analisis kuantitatif dilakukan secara matematis untuk menentukan kedalaman dan struktur geometri benda yang terpendam. Interpretasi anomali SP secara kuantitatif dibagi menjadi dua kategori Kategori yang pertama meliputi pemodelan kontinyu 2D dan 3D, kategori ini menggunakan rapat arus listrik, resistivitas, dan perkiraan kedalaman struktur benda sebagai parameter untuk melakukan proses modeling. Kategori kedua merupakan model geometri tetap sederhana, kategori ini menghitung 
kedalaman, sudut polarisasi benda, moment dipole listrik, dan bentuk struktur benda dibawah permukaan yang mempengaruhi data SP yang diamati diatas permukaan.

Hardi dan Mutmainna (2018) telah melakukan analisis kuantitaf anomali gravitasi dengan menggunakan metode least square. Teknik analisis yang digunakan adalah inversi linear dan non linear. Diperoleh hasil inversi data sintektik anomali gravitasi sangat berimpit dengan data sintetik hasil forward modeling . Hardi dan mutmainna (2018) menguji ketangguhan program yang telah dibuat dengan memberikan variasi noise pada data sintetik hasil forward modeling. Diperoleh hasil inversi parameter model memiliki nilai yang hampir sama dengan nilai para meter model yang sebenarnya dengan error yang sangat kecil. Begitu pula pada inversi non linear yang telah mereka lakukan.

Penelitian tentang anomali SP telah dilakukan oleh Hardi, dkk (2018). Mereka memodelkan anomali SP geometri tetap dengan analisis data menggunakan global optimasi Very Fast Simulated Annealing (VFSA). Hasil analisis yang diperoleh menunjukkan bahwa parameter model hasil inversi menunjukkan nilai yang hampir sama dengan nilai parameter model sintetik.

Dalam penelitian ini, kita meninjau daerah sesar yang ada di bawah permukaan bumi, jika kita menggangap bahwa sesar yang merupakan rekahan tanah telah terisi oleh mineral di bawah permukaan sehingga bagian rekahan yang berisi mineral tersebut akan membentuk suatu lempeng mineral. Adanya kandungan mineral akan mempengaruhi nilai anomali SP, akibat dari adanya mineral yang terperangkap dalam suatu rekahan yang berbentuk lempeng maka untuk kasus ini interpretasi anomali SP dapat dilakukan secara kuantitatif kategori geometri tetap.

Pada penelitian ini dilakukan akusisi data lapangan yang diduga terdapat sesar. Setelah data lapangan diperoleh maka akan dilakukan tahap analisis untuk memperkirakan parameterparameter yang mempengaruhi anomali SP akibat adanya sesar dibawah permukaan bumi. Tahap analisis data dilakukan dengan proses inversi menggunakan metode inversi non linier.

\section{METODE PENELITIAN}

\subsection{Formulasi Solusi Pemodelan Kedepan}

Perumusan anomali self-potensial yang disebabkan oleh polarisasi struktur yang berbentuk lempeng disetiap titik pengukuran $\mathrm{P}(\mathrm{x})$ disepanjang lintasan yang memotong struktur dapat dituliskan sebagai berikut:

$V\left(r_{1}, r_{2}, k\right)=k \log \frac{r_{1}^{2}}{r_{2}^{2}}$

Dimana $r_{1}^{2}$ dan $r_{2}^{2}$ secara berturut-berturut merupakan jarak dari titik pengamatan ke batas atas dan batas bawah struktur lempeng, dan $k$ merupakan moment dipole listrik dengan $I$ merupakan rapat arus dan $\rho$ merupakan resistivitas disekitar medium. Dengan menganggap $x_{0}$ sebagai posisi titik tengah dari lempeng maka perumusan umum untuk pemodelan kedepan oleh Asfahani dan Tlas (2005) dapat ditulis sebagai berikut:

$V(x)=k \ln \left[\frac{\left\{\left(x-x_{0}\right)+a \cos \beta\right\}^{2}+(h-a \sin \beta)^{2}}{\left\{\left(x-x_{0}\right)-a \cos \beta\right\}^{2}+(h+a \sin \beta)^{2}}\right]$

dengan $x$ merupakan sumbu koordinat pengukuran, $h$ merupakan kedalaman titik pusat lempeng, $a$ merupakan panjang lempeng dari titik tengah ke batas tepi, dan $\alpha$ merupakan sudut 
kemiringan lempeng terhadap arah horizontal yang berlawanan dengan arah jarum jam (Gambar $1)$.

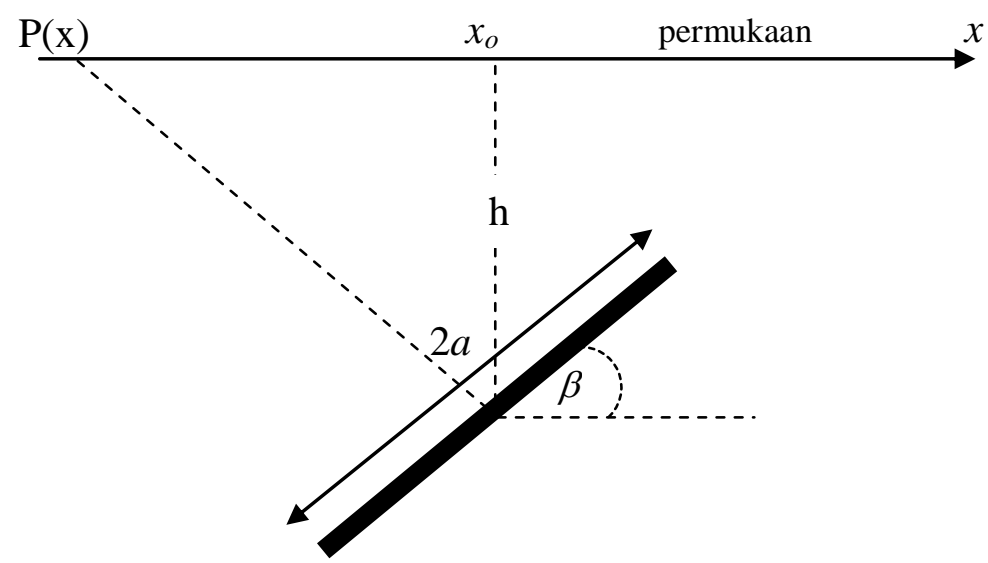

Gambar 1. Ilustrasi geometri lempeng di bawah permukaan tanah

\section{2 Metode Inversi Non-linier Pendekatan Linier}

Pada umumnya inversi dalam geofisika merupa inversi non linier. Namun demikian, inversi non-linier dapat diselesaikan menggunakan pendekatan linier. Dalam penelitian ini dilakukan perhitungan inversi untuk memperkirakan parameter model dari geometri lempeng menggunakan pemodelan inversi non-linier dengan metode least-square (LS) terbobot dan metode Levenberg-Marquardt (LM).

Pemberian bobot pada metode LS mengartikan jika ada data yang tidak terlalu akurat akan memberikan toleransi yang cukup besar pada data prediksi, agar data dapat dianggap cocok dengan data pengamatan. Solusi inversi non-linier berbobot ini dapat dituliskan dalam persamaan berikut: Hendra (2009)

$\mathbf{m}_{k+1}=\mathbf{m}_{k}+\left[\mathbf{J}_{k}^{T} \mathbf{w}_{e} \mathbf{J}_{k}\right]^{-1} \mathbf{J}_{k}^{T} \mathbf{w}_{e}\left(\mathbf{d}-G\left(\mathbf{m}_{0}\right)\right)$

$\mathbf{w}_{e}$ matriks pembobot yang merupakan matriks diagonal yang berisi varians data $\left[\mathbf{w}_{e}\right]=\left[\sigma_{i}^{-2}\right]$ dapat ditulis sebagai berikut:

$\mathbf{w}_{e}=\left[\begin{array}{cccc}w_{1} & 0 & \cdots & 0 \\ 0 & w_{2} & \cdots & 0 \\ \vdots & \vdots & \ddots & \vdots \\ 0 & 0 & \cdots & w_{n}\end{array}\right]$

Sedangkan solusi inversi metode LM dinyatakan sebagai berikut:

$\mathbf{m}_{k+1}=\mathbf{m}_{k}+\left(\mathbf{J}\left(\mathbf{m}^{k}\right)^{T} \mathbf{J}\left(\mathbf{m}^{k}\right)+\lambda \mathbf{I}\right)^{-1} \mathbf{J}\left(\mathbf{m}^{k}\right)^{T} \mathbf{F}\left(\mathbf{m}^{k}\right)$

Untuk kedua solusi inversi di atas, notasi $k$ menunjukan jumlah iterasi, iterasi ke $(k+1)$ merupakan model pada iterasi sebelumnya yaitu iterasi ke $k$ yang diperbarui dengan suatu faktor koreksi, J merupakan matriks Jacobian, $T$ menyatakan matriks transpos.

$\mathbf{J}=\left[\begin{array}{ccc}\frac{\partial F_{i}(\mathbf{m})}{\partial \mathrm{m}_{1}} & \cdots & \frac{\partial F_{i}(\mathbf{m})}{\partial \mathrm{m}_{m}} \\ \vdots & \ddots & \vdots \\ \frac{\partial F_{n}(\mathbf{m})}{\partial \mathrm{m}_{1}} & \cdots & \frac{\partial F_{n}(\mathbf{m})}{\partial \mathrm{m}_{m}}\end{array}\right]$ 
Pada metode LM notasi $\lambda$ merupakan parameter peredam untuk menjaga proses inversi agar tetap stabil dan $\mathbf{F}(\mathbf{m})$ merupakan vektor dari selisih data observasi dan hasil inversi.

Kedua inversi non-linier menggunakan pendekatan linier ini telah diuji menggunakan data sintetik anomali SP geometri lempeng dan diperoleh nilai estimasi parameter yang cukup mendekati dengan nilai data sintetik dalam Fajriani (2016)

\subsection{Metodologi}

Struktur sesar dapat ditandai dengan adanya perbedaan litologi yang terlihat diatas permukaan, dan dapat pula terlihat adanya perbedaan kedalaman struktur bawah permukaan dengan litologi yang sama jika dilihat dari penampang geologi. Data anomali SP diperoleh dengan melakukan akuisisi data lapangan. Lintasan pengukuran dilakukan dengan memotong struktur sesar. Dari hasil akuisisi data lapangan diperoleh anomali SP yang cukup fluktuatif, keadaan ini kemungkinan karena adanya perbedaan porositas maupun kandungan fluida batuan dibawah permukaan tanah. Dari anomali yang terukur terlihat adanya penajaman anomali yang diperkirakan anomali tersebut disebabkan oleh keberadaan sesar. Anomali SP dari data lapangan ditunjukkan oleh gambar 2 .

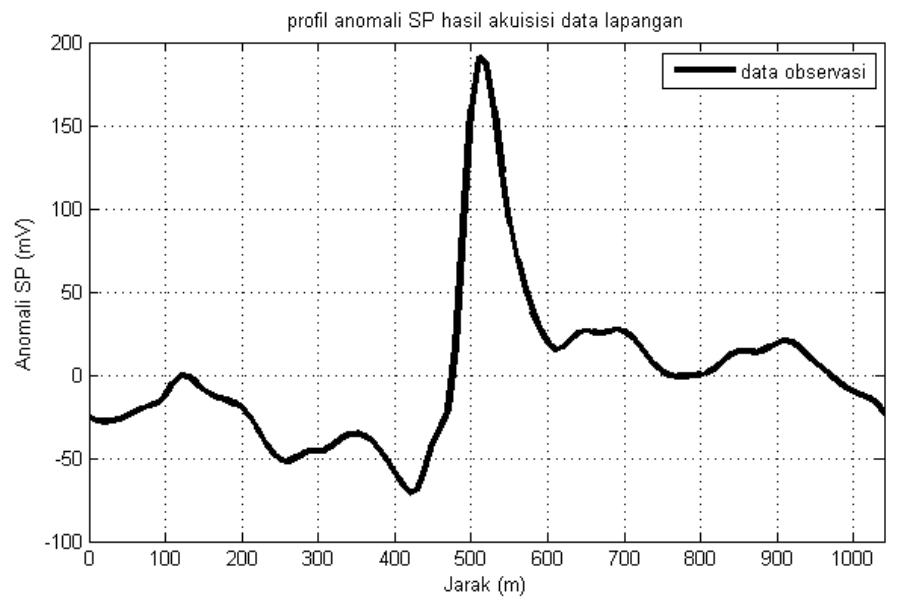

Gambar 2. Profil anomali SP hasil akuisisi data lapangan

Data anomali SP pada gambar 2 merupakan data observasi yang telah diperhalus untuk menghilangkan efek perbedaan jenis tanah dan mempertajan nilai anomali. Selanjutnya data observasi ini digunakan dalam proses inversi untuk mengestimasi nilai parameter yang mempengaruhi anomali.

\section{HASIL DAN PEMBAHASAN}

Hasil akuisisi data lapangan diperoleh data observasi yang menunjukkan penajaman anomali disekitar jarak $400 \mathrm{~m}$ sampai $620 \mathrm{~m}$. Jarak anomali tersebut sesuai dengan jarak pengukuran saat memotong struktur sesar di lapangan, sehingga dapat diasumsikan anomali SP tersebut diakibatkan karena adanya struktur sesar di bawah permukaan bumi.

Data observasi yang diperoleh selanjutnya dilakukan pemodelan inversi. Dalam proses inversi, parameter estimasi yang diperkirakan yaitu moment dipol $k=20 \mathrm{mV}$, panjang setengah lempeng $a=10 \mathrm{~m}$, kedalaman pusat lempeng $h=10 \mathrm{~m}$, titik keberadaan pusat lempeng $x_{0}=10$ $\mathrm{m}$, dan sudut polarisasi terhadap bidang horizontal $\beta=10^{\circ}$. 
Hasil inversi menampilkan kurva data perhitungan menggunakan inversi non-linier dengan pendekatan linier berhasil mengikuti pola data lapangan dengan baik dan proses inversinya memerlukan waktu yang relatif singkat, metode LS terbobot memerlukan waktu 3.42 detik dan metode LM membutuhkan waktu 0.075 detik.

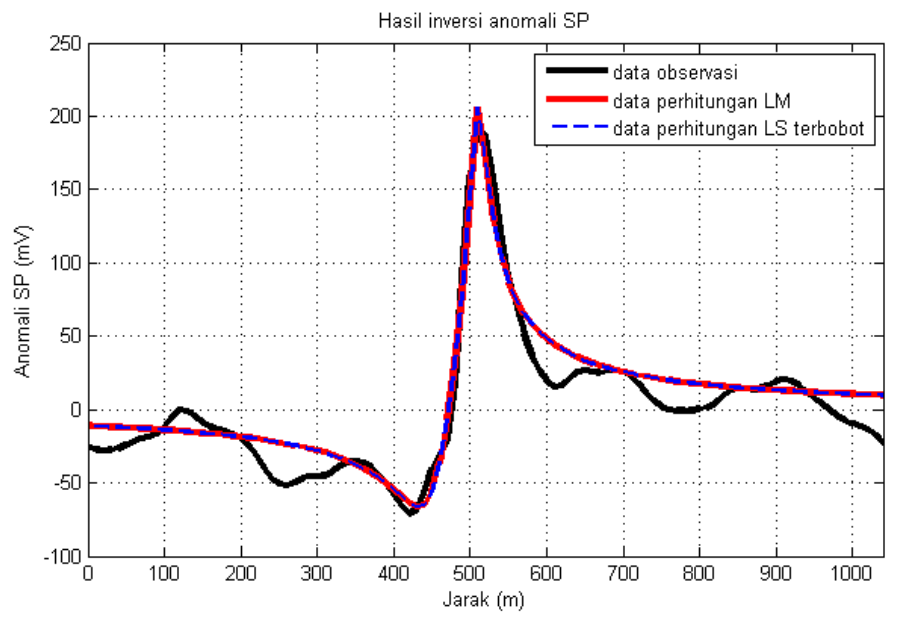

Gambar 3. Hasil inversi data observasi anomali SP

Gambar 3 menunjukkan pola hasil inversi menggunakan metode least-square terbobot dan Levenberg-Marquardt saling overlapping. Dari kurva tersebut dapat dipastikan bahwa hasil perkiraan parameter diantara kedua metode tersebut diperoleh nilai yang sama atau mendekati. Nilai parameter hasil perhitungan kedua metode inversi dapat dilihat pada tabel 1.

Tabel 1 Perbandingan nilai parameter data hasil perhitungan metode LS terbobot dan LM

\begin{tabular}{|c|c|c|}
\hline Parameter model & Hasil LS terbobot & Hasil LM \\
\hline$k(\mathrm{mV})$ & $45.78090+-0.21219$ & $45.78092+-0.67099$ \\
\hline$a(\mathrm{~m})$ & $32.26527+-0.13895$ & $32.26526+-0.43941$ \\
\hline$h(\mathrm{~m})$ & $20.00255+-0.08162$ & $20.00255+-0.25809$ \\
\hline$\beta\left(^{\circ}\right)$ & $9.01328+-0.11554$ & $5.87168+-0.36538$ \\
\hline$x_{o}(\mathrm{~m})$ & $480.62265+-0.11557$ & $480.62265+-0.36547$ \\
\hline
\end{tabular}

Dari tabel 1 terlihat bahwa hasil perhitungan kedua metode inversi tersebut memiliki nilai yang sama. Namun terdapat perbedaan hasil perhitungan terhadap nilai kemiringan sudut $\beta$. Walaupun demikian nilai hasil perhitungan sudut dari kedua metode tersebut tidak terlalu jauh berbeda, nilainya masih saling mendekati.

\section{KESIMPULAN}

Dari hasil penelitian dapat disimpulkan bahwa:

- Inversi non-linier menggunakan pendekatan linier mampu memberikan hasil yang baik dalam menentukan parameter model dari anomali SP akibat dari keberadaan struktur sesar.

- Metode least-square terbobot dan Levenberg-Marquardt mampu mengikuti pola hasil data pengukuran di lapangan. 
- Kedua metode inversi tersebut efisien karena proses perhitungannya yang relatif singkat serta nilai parameter model struktur lempeng hasil perhitungan kedua metode tersebut menunjukkan hasil yang sama yaitu moment dipole sebesar $45.78 \mathrm{mV}$, panjang setengah lempeng sebesar $32.26 \mathrm{~m}$, kedalaman lempeng $20 \mathrm{~m}$, jarak pusat lempeng berada di $480 \mathrm{~m}$ dari titik awal pengukuran di lapangan.

- Terdapat sedikit selisih perhitungan pada nilai kemiringan sudut lempeng yaitu pada metode least-square terbobot kemiringan lempeng sebesar $9^{\circ}$ sedangkan pada metode Levenberg-Marquardt kemiringan lempeng sebesar $5.8^{\circ}$.

\section{DAFTAR PUSTAKA}

Asfahani, J. Tlas, M .,2005, A Constrained Nonlinear Inversion Approach to Quantitative Interpretation of Self-Potential Anomalies Caused by Cylinders Spheres and Sheet-like Structures, Pure Appl. Geophys. 162 609-624

Fajriani dan Srigutomo, W., 2016, Perbandingan Inversi Non-Linier Untuk Interpretasi Anomali Self-Potential Model Fixed Geometry: Metode Least-Square, Gauss-Newton, dan Levenberg-Marquardt, Prosiding Simposium Nasional Inovasi dan Pembelajaran Sains 2016, Program Studi Magister Pengajaran Fisika, Fakultas Matematika dan Ilmu Pengetahuan Alam, Institut Teknologi Bandung, Bandung

Hamzah, H., Mutmainnah., 2018, Analisis Kuantitatif Anomali Gravitasi Metode Least Square pada Terapan Mata Kuliah Analisa Numerik, Jurnal Saintifik, No.1, Vol.4, 24-30, DOI:10.31605/saintifik.v4i1.140, http://jurnal.unsulbar.ac.id/saintifik

Hamzah, H., Heriyanto, M., Srigutomo, W. Pemodelan Anomali Self-Potential Geometri Tetap Dan Inversi Global Optimasi Very Fast Simulated Annealing. Phydagogic, No.1, Vol.1, 2429, DOI: 10.31605/phy.v1i1.222, http://ojs.unsulbar.ac.id/index.php/phy

Hendra, G., 2009, Pengantar pemodelan inversi geofisika, Himpunan Ahli Geofisika Indonesia (HAGI), Institut Teknologi Bandung.

Telford, W. M., 1990, Applied geophysics second edition, Cambridge University Press, Australia. 